\title{
Analisis Penerapan Pengendalian Biaya Tenaga Kerja dalam Penentuan Biaya Gaji yang Bersumber dari Dana Bopda (SD Dumas Surabaya)
}

\author{
Dhea Wahyuni Apriyanti \\ Jurusan Akuntansi Fakultas Ekonomi dan Bisnis \\ Universitas Bhayangkara Surabaya, Indonesia
}

DOI: $10.46821 /$ equity.v1i1.204

\begin{abstract}
ABSTRAK
Tujuan penelitian adalah untuk mengetahui penerapan pengendalian biaya tenaga kerja dalam penentuan biaya gaji yang bersumber dari Dana BOPDA pada SD Dumas Surabaya. Analis bagian penetapan penggajian yang bersumber dari dana BOPDA dengan menggunakan metode pengendalian waktu. Penelitian ini merupakan penelitian deskriptif kualitatif. Lokasi penelitian ini pada SD Dumas Surabaya dengan subjek penelitiannya adalah kepala sekolah, bendahara dan Petugas IT. Teknik pengumpulan data penelitian melalui observasi dan wawancara. Teknis analis data yang digunakan adalah : identifikasi data penggajian, penetapan gaji guru, pengendalian penetapan gaji dan menarik kesimpulan serta saran. Hasil dari penelitian yang sudah dilakukan bahwa dalam penerapan pengendalian biaya tenaga kerja dengan menerapkan teori pengendalian waktu, SD Dumas Surabaya masih belum optimal dikarenakan dalam pencatatan presensi kehadiran belum dilakukan secara baik sehingga berpengaruh terhadap jumlah gaji yang tidak sesuai dengan yang seharusnya.
\end{abstract}

Kata kunci: Pengendalian Biaya Tenaga Kerja, Dana BOPDA, pengendalian waktu

\begin{abstract}
The purpose of the research was to find out the application of labor cost control in determining salary costs sourced from bopda funds at SD Dumas Surabaya. Analysts in the payroll department sourced from BOPDA funds using time control methods. This research is qualitative descriptive research. The location of this research at SD Dumas Surabaya with its research subjects are the principal, treasurer and IT Officer. Research data collection techniques through observation and interview. Technical data analysts used are: identification of payroll data, determination of teacher salaries, control of salary determination and drawing conclusions and suggestions. The result of the research that has been done that in the application of labor cost control by applying the theory of time control, SD Dumas Surabaya is still not optimal because in the recording of attendance presensi has not been done properly so as to affect the amount of salary that is not appropriate.
\end{abstract}

Keywords: Labor Cost Control, BOPDA Fund, Time Control

*Corresponding Author:

Email: dheawapriyanti@gmail.com 


\section{PENDAHULUAN}

Salah satu anggaran pengunaan dana BOPDA atau Hibah ini adalah digunakan sebagai sumber dari gaji guru. Pasalnya, pemerintah saat ini menganjurkan gaji guru sesuai dengan anggaran UMR yang berlaku guna terjaminnya kesejahteraan Tenaga Pendidik di Surabaya. Sebagai sekolah yang bernaung pada Yayasan, SD Dumas mengakali agar semua guru memperoleh gaji yang sesuai dengan UMR yang berlaku dengan memperhitungkan berapa kemampuan Yayasan untuk menganggarkan gaji setiap guru. Jika dalam anggaran dana yang sudah dirancang yayasan dirasa jauh dari nilai UMR, maka kekurangan dana gaji akan di ambilkan dari anggaran dana BOPDA. Dalam hal ini, ada beberapa syarat yang harus di penuhi Tenaga Pendidik agar bisa mendapatkan anggaran gaji dari BOPDA adalah : guru tidak digaji dari dana BOPNAS, guru sudah terdaftar pada SKPBM. Untuk bisa terdafta pada SKPBM Tenaga Pendidik dituntut harus linier dan sudah memiliki masa kerja minimal 1 tahun. Penelitian ini bertujuan untuk mengetahui bagaimana penerapan pengendalian biaya tenaga kerja dalam penentuan biaya gaji yang bersumber dari dana BOPDA.

\section{LANDASAN TEORI}

\section{Pengertian Pengendalian Waktu}

Pengendalian waktu bertujuan untuk mengetahui apakah waktu untuk mengerjakan sesuai pekerjaan sesuai atau tidak dengan rencana.

\section{Pengertian Biaya}

Biaya adalah pengorbanan sumber ekonomis yang diukur dalam satuan uang. Baik yang telah terjadi, sedang terjadi atau yang kemungkinan akan terjadi untuk tujuan tertentu (Mulyadi, 2001).

\section{Pengertian BOPDA}

Bantuan Operasioanal Pendidikan Daerah adalah bantuan yang diberikan oleh pemerintah daerah. Bantuan ini memiliki sumber dana yang berasal dari APBD (Anggaran Pendapatan Belanja Daerah).

\section{Tujuan BOPDA}

Peraturan Menteri Pendidikan dan Kebudayaan No. 1 Tahun 2018, untuk tingkatan pendidikan Sekolah Dasar memiliki tujuan guna : a. Untuk membantu pendanaan biaya operasi non personil sekolah, akan tetapi masih ada beberapa pembiayaan personil yang masih dibayarkan dari dana bos. b. Membebaskan pungutan biaya operasi sekolah bagi peserta didik SD/SDSLB/SMP/SMPSLB yang diselenggrakan oleh pemerintah pusat atau daerah. c. Meringankan beban biaya operasi sekolah bagi peserta didik SD/SDSLB/SMP/SMPSLB yang diselenggarakan oleh masyarakat ; dan/ atau, d. Membebaskan pungutan peserta didik yang orangtua/walinya tidak mampu pada SD/SDSLB/SMP/SMPSLB yang diselenggarakan oleh masyarakat. 


\section{Pengunaan BOPDA}

Penggunaan dana BOPDA dianggarkan untuk : a. pengadaan barang dan jasa untuk kegiatan siswa dan pembelian ATK; b. perbaikan ringan; c. gaji guru. Gaji guru dianggarkan dari dana BOPDA dengan tujuan agar bisa menerima gaji tiap bulan.

\section{Pelaksanaan BOPDA}

Pelaksanaan Anggaran BOPDA harus disesuaikan dengan Rencana Kegiatan dan Anggaran Sekolah (RKAS) yang sudah ada tiap bulannya. Jadi antara RAPBS dan RKAS dapat diamati apakah sudah berjalan sesuai dengan anggaran yang diajukan.

\section{METODE PENELITIAN}

Lokasi penelitian terletak pada SD Dumas Surabaya berdiri sejak tahun 30 Juni 1977. Berada ditengah pemukiman penduduk mayoritas dari suku Madura yang padat, kumuh dan miskin dengan latar belakang pendidikan yang rendah dan tingkat kepedulian terhadap pendidikan yang relatif minim.. Penelitian dilaksanakan selama 4 bulan dimulai pada Maret 2021 hingga Juni 2021. Penelitian ini dilakukan dengan menggunakan pendekatan kualitatif. Untuk metode pengumpulan data dilakukan dengan melalui Observasi : dalam observasi, peneliti mengumpulkan beberapa data pada SD Dumas Surabaya yang berkaitan dengan Anggaran penggajian guru dengan sumber dana BOPDA. Wawancara : teknik wawancara guna mengumpulkan data real dilakukan setiap penelitian. Wawancara dilakukan kepada Kepala Sekolah, Bendahara, dan Tenaga IT. Pada analisis data peneliti menggunakan metode triangulasi, Dalam hal ini, peneliti melakukan metode wawancara yang ditunjang dengan metode observasi pada saat wawancara dilakukan. Hal ini di dapat dari : (a) Membandingkan hasil wawancara dan data observasi yang telah didapat, (b) Membandingkan hasil wawancara dari satu narasumber dengan nasarumber yang lain, (c) Membandingkan data observasi dengan keadaan nyata.

\section{HASIL DAN PEMBAHASAN}

Pada penelitian ini ditemukan hasil penelitian terdapat prosedur penggajian guru pada SD Dumas Surabaya pelaksanaan penggajian yang dilakukan SD Dumas Surabaya sebagai berikut :

1. Mengentri data Guru dan Karyawan (meliputi riwayat pendidikan),

2. Membuat jadwal SKPBM (Surat Keterangan Perintah Belajar Mengajar ) guna penentuan banyak jam mengajar.

3. Mengentri daftar hadir Guru dan Karyawan,

4. Perekapan daftar hadir (untuk menghitung jumlah kehadiran),

5. Penentuan Gaji. 
Tabel 1. Contoh Pembagian Beban Mengajar SD Dumas Surabaya

\begin{tabular}{|c|c|c|c|c|c|c|c|c|c|}
\hline \multirow[b]{2}{*}{ NO } & \multirow[b]{2}{*}{ NAMA GURU } & \multirow[b]{2}{*}{$\begin{array}{l}\text { STATUS } \\
\text { GURU }\end{array}$} & \multicolumn{6}{|c|}{$\begin{array}{l}\text { RINCIAN BEBAN MENGAJAR PER- } \\
\text { MINGGU }\end{array}$} & \multirow[b]{2}{*}{$\begin{array}{l}\text { JML JAM } \\
\text { MENGAJAR }\end{array}$} \\
\hline & & & KLS & $\mathrm{KLS}_{2}$ & $\mathrm{KLS}_{3}$ & $\underset{4}{\mathrm{KLS}}$ & $\underset{5}{\mathrm{KLS}}$ & $\underset{6}{\mathrm{KLS}}$ & \\
\hline 1 & $\begin{array}{l}\text { SHANTY ERNA } \\
\text { MELYATY, S.Pd }\end{array}$ & GTY & & & & & & & \\
\hline 2 & $\begin{array}{l}\text { DHEA } \\
\text { WAHYUNI } \\
\text { APRIYANTI }\end{array}$ & GTT & & & & & & & \\
\hline 3 & ABDUR ROHIM & GTT & & & & & & & \\
\hline 4 & $\begin{array}{l}\text { MIFTAKHUL } \\
\text { JANNAH }\end{array}$ & GTT & & & & & & & \\
\hline 5 & $\begin{array}{l}\text { ERLIA KUMALA } \\
\text { SARI, S.Pd }\end{array}$ & GTY & & & & & & & \\
\hline 6 & $\begin{array}{l}\text { IRMA } \\
\text { FAHRIYANI, } \\
\text { S.Pd.I }\end{array}$ & GTY & & & & & & & \\
\hline
\end{tabular}

Sumber: Data Diolah (2021)

Tabel 2. Contoh Daftar Kehadiran Guru SD Dumas Surabaya

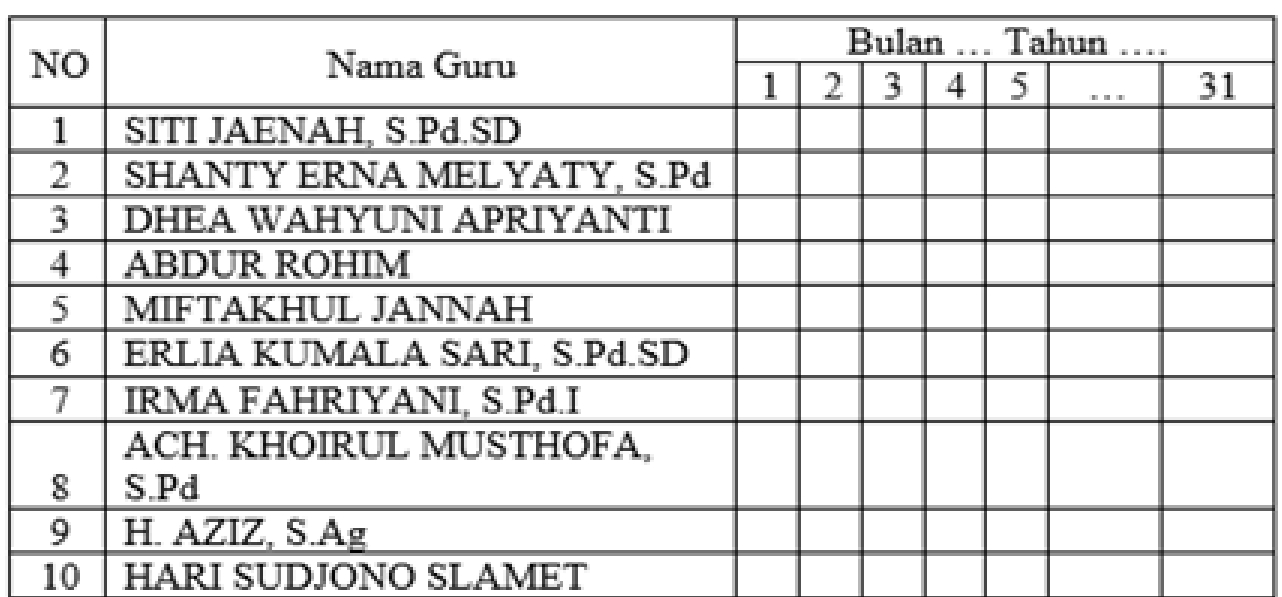

Sumber: Data Diolah (2021)

Tabel 3. Contoh Rekapitulasi Kehadiran Guru SD Dumas Surabaya

\begin{tabular}{|c|c|c|c|c|c|}
\hline \multirow{3}{*}{ No } & \multirow{3}{*}{ Nama Guru } & \multicolumn{4}{|c|}{ Hari } \\
\hline & & \multicolumn{3}{|c|}{ ABSENSI } & \multirow{2}{*}{ PRESENSI } \\
\hline & & $\mathrm{S}$ & I & A & \\
\hline 1 & SITI JAENAH, S.Pd.SD & & & & \\
\hline 2 & SHANTY ERNA MELYATY, S.Pd & & & & \\
\hline 3 & DHEA WAHYUNI APRIYANTI & & & & \\
\hline 4 & ABDUR ROHIM & & & & \\
\hline 5 & MIFTAKHUL JANNAH & & & & \\
\hline 6 & ERLIA KUMALA SARI, S.Pd.SD & & & & \\
\hline 7 & IRMA FAHRIYANI, S.Pd.I & & & & \\
\hline 8 & $\begin{array}{l}\text { ACH. KHOIRUL MUSTHOFA, } \\
\text { S.Pd }\end{array}$ & & & & \\
\hline 9 & H. AZIZ, S.Ag & & & & \\
\hline 10 & HARI SUDJONO SLAMET & & & & \\
\hline
\end{tabular}

Sumber: Data Diolah (2021) 
Pada saat tahun ajaran baru, SD Dumas Surabaya menerbitkan Surat Keterangan Perintah Belajar Mengajar yang dapat dilihat pada Tabel 1. Dalam penerbitan surat tersebut, SD Dumas Surabaya melakukan prosedur adalah : (a) Kepala sekolah bertugas untuk menganalisa data guru dan pegawai yang terdiri dari ijazah dan bidang studi yang diampuh. (b) Kepala sekolah selanjutnya melakukan perjanjian kerja dengan dewan guru yang disetujui oleh kedua belah pihak. (c) Menentukan banyaknya jam mengajar melalui penerbitan Surat Keputusan Pembagian Jam Mengajar.

SD Dumas Surabaya memiliki kebijakan atas pencatatan waktu hadir, karena presentase kehadiran sangat mempengaruhi dalam penganggaran penggajian. Saat Dewan Guru berhalangan hadir, dapat menyampaikan permohonan ijin melalui telepon sekolah atau pesan singkat. Jika berhalangan hadir dan tidak memberikan alasan yang urgent atau sangat mendesak, dianggap alpha (Tabel 2 dan Tabel 3).

Berdasarkan petunjuk teknis penggunaan dana BOPDA, alokasi dana yang digunakan untuk penggajian guru dapat dilihat pada Tabel 4 dan Tabel 5. Pada penggajian guru terdapat perbedaaan perhitungan gaji terdapat tambahan intensif bagi guru yang sudah menempuh pendidikan S1. Perbedaan data penggajian tersebut dapat dilihat pada Tabel 6 .

Pengendalian internal atas gaji dan upah merupakan seluruh kebijakan dan prosedur yang berkaitan dengan transaksi gaji dan upah yang diterapkan untuk mendapatkan kenyakinan yang memadai. Salah satu pengendalian dapat dinilai dari tanggung jawab yang dibebankan kepada guru dan karyawan. Penerapan pengendalian atas gaji dan upah yang memadai diharapkan mampu menciptakan informasi keuangan yang lebih andal serta membantu dalam pelaporan hasil pengendalian gaji pada pihak yang berwenang yaitu Dinas Pendidikan.

Tabel 4 menunjukkan bahwa penggajian pada SD Dumas Surabaya, dana penggajian diperoleh dari dana BOPDA sebanyak $75 \%$ dan sisanya diperoleh dari dana BOS. Dana BOPDA digunakan sebagai gaji guru dan sisanya di gunakan sebagai biaya operasional sekolah yang dibantu dengan dana BOS. Untuk perhitungan penggajian didapatkan dari jumlah jam mengajar dikalikan dengan upah per-jam mengajar (Tabel 5). Untuk system penggajian masih menggunakan system yang manual dan dilakukan pembagian gaji setiap bulannya pada tanggal 30 atau 31 (Tabel 6).

Tabel 4. Alokasi Dana Penggajian Dana BOPDA

\begin{tabular}{|c|c|c|c|c|}
\hline $\begin{array}{c}\text { JUMLAH } \\
\text { SISWA }\end{array}$ & $\begin{array}{c}\text { DANA YANG } \\
\text { DITERIMA }\end{array}$ & $\begin{array}{c}\text { TOTAL DANA YANG } \\
\text { DITERIMA }\end{array}$ & PRESENTASE & JMLAH \\
\hline 120 & Rp $1.020 .000,00$ & $\mathrm{Rp} \quad 122.400 .000,00$ & $75 \%$ & $\operatorname{Rp} 91.800 .000,00$ \\
\hline
\end{tabular}

Sumber: Data Diolah (2021) 
Tabel 5. Perangkat Pembayaran Gaji dari Dana BOPDA

\begin{tabular}{|c|c|c|c|c|c|c|}
\hline NO & NAMA & $\begin{array}{l}\text { JAM } \\
\text { MENGAJAR }\end{array}$ & \multicolumn{2}{|c|}{$\begin{array}{l}\text { GAII TIAP JAM } \\
\text { MENGAJAR }\end{array}$} & \multicolumn{2}{|c|}{$\begin{array}{l}\text { GAII POKOK PER } \\
\text { BULAN }\end{array}$} \\
\hline 1 & SITI JAENAH, S.Pd.SD & 7 & $\mathrm{Rp}$ & $179.187,00$ & Rp & $1.254 .309,00$ \\
\hline 2 & $\begin{array}{l}\text { SHANTY ERNA MELYATY, } \\
\text { S.Pd.SD }\end{array}$ & 7 & Rp & $179.187,00$ & Rp & $1.254 .309,00$ \\
\hline 3 & ERLIA KUMALA SARI, S.Pd.SD & 7 & Rp & $179.187,00$ & Rp & $1.254 .309,00$ \\
\hline 4 & MIFTAHUL JANNAH & 7 & Rp & $179.187,00$ & Rp & 1.254.309, bo \\
\hline 5 & DHEA WAHYUNI APRIYANTI & 7 & Rp & $179.187,00$ & Rp & $1.254 .309,00$ \\
\hline 6 & ABDUR ROHIM & 7 & $R p$ & $179.187,00$ & Rp & $1.254 .309,00$ \\
\hline
\end{tabular}

Sumber: Data Diolah (2021)

Tabel 6. Perangkat Gaji dengan Tunjangan Pendidikan

\begin{tabular}{|c|c|c|c|c|c|c|}
\hline NO & NAMA & $\begin{array}{l}\text { JUMLAH } \\
\text { JAM } \\
\text { MENGAJAR }\end{array}$ & $\begin{array}{l}\text { GAII TIAP } \\
\text { JAM } \\
\text { MENGAJAR }\end{array}$ & $\begin{array}{l}\text { GAII POKOK } \\
\text { PER BULAN }\end{array}$ & $\begin{array}{l}\text { TUNJANGAN } \\
\text { PENDIDIKAN }\end{array}$ & JUMLAH \\
\hline 1 & $\begin{array}{l}\text { SITI JAENAH, } \\
\text { S.Pd.SD }\end{array}$ & 7 & $\begin{array}{l}\text { Rp } \\
179.187,00\end{array}$ & $\begin{array}{l}\text { Rp } \\
1.254 .309,00\end{array}$ & $\begin{array}{l}\text { Rp } \\
50.000,00\end{array}$ & $\begin{array}{l}\text { Rpp } \\
1.304 .309,00\end{array}$ \\
\hline 2 & $\begin{array}{l}\text { SHANTY ERNA } \\
\text { MELYATY, S.Pd.SD }\end{array}$ & 7 & $\begin{array}{l}\text { Rp } \\
179.187,00\end{array}$ & $\begin{array}{l}\text { Rp } \\
1.254 .309,00\end{array}$ & $\begin{array}{l}\text { Rp } \\
50.000,00\end{array}$ & $\begin{array}{l}\text { Rpp } \\
1.304 .309,00\end{array}$ \\
\hline 3 & $\begin{array}{l}\text { ERLIA KUMALA } \\
\text { SARI, S.Pd.SD }\end{array}$ & 7 & $\begin{array}{l}\mathrm{Rp} \\
179.187,00\end{array}$ & $\begin{array}{l}\text { Rp } \\
1.254 .309,00\end{array}$ & $\begin{array}{l}\text { Rp } \\
50.000,00\end{array}$ & $\begin{array}{l}\text { Rp } \\
1.304 .309,00\end{array}$ \\
\hline 4 & $\begin{array}{l}\text { MIFTAHUL } \\
\text { JANNAH }\end{array}$ & 7 & $\begin{array}{l}\text { Rp } \\
179.187,00\end{array}$ & $\begin{array}{l}\text { Rp } \\
1.254 .309,00\end{array}$ & - & $\begin{array}{l}\text { Rpp } \\
1.254 .309,00\end{array}$ \\
\hline 5 & $\begin{array}{l}\text { DHEA WAHYUNI } \\
\text { APRIYANTI }\end{array}$ & 7 & $\begin{array}{l}\text { Rp } \\
179.187,00\end{array}$ & $\begin{array}{l}\text { Rp } \\
1.254 .309,00\end{array}$ & - & $\begin{array}{l}\text { Rpp } \\
1.254 .309,00\end{array}$ \\
\hline 6 & ABDUR ROHIM & 7 & $\begin{array}{l}\text { Rp } \\
179.187,00\end{array}$ & $\begin{array}{l}\text { Rp } \\
1.254 .309,00\end{array}$ & - & $\begin{array}{l}R p \\
1.254,309,00\end{array}$ \\
\hline
\end{tabular}

Sumber: Data Diolah (2021)

Tabel 6 menjelaskan bahwa dalam penggajian terdapat perbedaan perhitungan yang disebabkan oleh adanya tunjangan pendidikan bagi guru atau karyawan yang telah menempuh pendidikan Strata 1 (S1) sebesar Rp 50.000 pada setiap bulannya. Untuk hasil rekapitulasi jumlah presensi, saat penelitian ditemukan penemuan bahwasanya perhitungan presensi guru hanya digunakan senagai formatitas saja yang seharusnya, jika terdapat guru atau pegawai yang alpha akan diperlakukan system pemotongan gaji. Namun pada kenyataannya hal itu tidak terealisasi di SD Dumas Surabaya.

\section{SIMPULAN}

Berdasarkan hasil penelitian yang telah dijabarkan pada Analisis Penerapan Pengendalian Biaya Tenaga Kerja Dalam Penentuan Biaya Gaji Yang Bersumber Dari Dana Bopda (SD Dumas Surabaya) sebagai berikut : (1) Kelemahan dalam penerapan teori pengendalian waktu SD Dumas Surabaya masih belum optimal sehingga perhitungan gaji guru di pukul sama rata. (2) Kelemahan dalam prosedur penggajian terdapat pencatatan presensi yang seharusnya diterapkan namun hanya digunakan sebagai formalitas saja. Sehingga berpengaruh terhadap jumlah gaji yang tidak sesuai dengan yang seharusnya. Saran dari penelitian ini adalah penerapan pengendalian biaya pada SD Dumas sudah baik, tetapi masih ada beberapa hal yang harus diperbaiki. Terutama pada system penggajian yang masih 
dilakukan secara manual yang harusnya dilakukan dengan system yang canggih seperti menggunakan system transfer sehingga memudahkan dalam pencatatan pembukuan dan pelaporan. Diharapkan adannya perbaikan pada pencatatan presensi dengan menggunakan system yang lebih canggih agar mendapatkan data presensi yang dapat dipertanggungjawabkan sehingga dalam pembagian penggajian dapat sesuai dengan yang seharunya dibayarkan. Diharapkan kedepannya SD Dumas dapat menerapkan pengunaan metode pengendalian waktu dalam perhitungan gaji guna menciptkan perhitungan gaji yang dapat dipertanggungjawabkan.

\section{DAFTAR PUSTAKA}

Hamidi, 2010, Metode Penelitian Kualitatif. Malang: UMM Press. Komaruddin, 2001. Ensilopedia Manajemen, Edisi ke 5, Jakarta, umi Aksara.

Mulyadi, 2001, Akuntansi Manajemen, Edisi ketiga, Jakarta, Salemba Empat.

Mulyadi. 2007. Sistem Perencanaan dan Pengendalian Manajemen. Jakarta: salemba. Empat.

Nurdin Usman, 2002, Konteks Implementasi Berbasis Kurikulum, Jakarta: Grasindo, hal 70.

Sugiono, 2016, Metode Penelitian Kuantitatif, Kualitatif dan R\&D, Bandung: Alfabeta, hal 60.

Sugiono, 2016, Metode Penelitian Kuantitatif, Kualitatif dan R\&D, Bandung: Alfabeta, hal 9.

Sugiono, 2016, Metode Penelitian Kuantitatif, Kualitatif dan R\&D, Bandung: Alfabeta, hal 224.

Sugiyono, 2016, Metode Penelitian Kuantitatif, Kualitatif dan $R \& D$, Bandung: Alfabeta. hal 8.

Peraturan Walikota Surabaya Nomor 65 Tahun 2015. Petunjuk Tekni Pemberian Hibah Biaya Pendidikan Daerah, Tahun 2015.

Peraturan Walikota Surabaya Nomor 13 Tahun 2012. Petunjuk Teknis Pengelolaan Biaya Operasional Pendidikan, Tahun 2012. 